\title{
The Effect of Ice-Bag Applied to Femoral Region of Individuals with Percutaneous Coronary Intervention on Local Vascular Complications and Low Back-Pain
}

\author{
Gülsüm Nihal Çürük ${ }^{1}$, Sultan Taşc1 ${ }^{2}$, Ferhan Elmalı ${ }^{3}$, Abdurrahman Oguzhan ${ }^{4}$, Nihat Kalay ${ }^{4}$ \\ ${ }^{1}$ Izmir University of Economics, Faculty of Health Sciences, Izmir, Turkey \\ ${ }^{2}$ Erciyes University, Faculty of Health Sciences, Kayseri, Turkey \\ ${ }^{3}$ Izmir Katip Çelebi University, Faculty of Medicine, Izmir, Turkey \\ ${ }^{4}$ Erciyes University, Faculty of Medicine, Kayseri, Turkey \\ (Corresponding Author; Gülsüm Nihal Çürük, guleser38@gmail.com)
}

\begin{abstract}
Objectives: The main aim is of this paper are to determine the effect of applying local ice-bag on local vascular complications and on low back-pain in individuals, who were applied coronary invasive intervention.

Background: One of the methods used in both diagnosis and treatment of coronary artery disease is percutaneous coronary intervention (PCI). The complications which develop due to these interventions are important causes of morbidity. After coronary invasive interventions, sandbag is prescribed in order to minimize vascular complications, but this often leads to back pain.

Methods: The study was conducted with 298 patients (104 in ice-bag group, 100 in sandbag group and 94 in no application group) who were eligible for the study criteria. The data were collected with Patient Identification Form, Vascular Complications Form, Vital Signs Form and Visual Analog Scale (VAS). Local vascular complications developing at the hospital were called as "first follow-up complications", complications developing after one week from the discharge were called as "second follow-up complications" and if complications developed both at the hospital and after discharge, these complications were called as "total complications". The low back-pain that patients fell was evaluated 5 times, first immediately after the procedure and then 2-4 and 6 hours after the procedure and finally immediately before discharge from the hospital. Signed consent forms for the study were obtained from patients after the ethics committee approval.

Results: In the first follow-up, the group who had least complications was the ice-bag group $(p>0.05)$ and at the second and total follow-up, the group who had least complications was ice-bag group ( $p<0.001)$. VAS score of all groups was gradually increased and lowest increase was in the ice-bag group. Follow up times and VAS score of groups were determined as statistically significant $(p<0.001)$.

Conclusion: Applying ice-bag to individuals who were applied coronary invasive intervention is an effective method for reducing complication development and low back-pain. Therefore, this approach is recommended to be included in nursing practices.
\end{abstract}

Key Words: Percutaneous coronary intervention, Local vascular complications, Cold application, Low backpain, Nursing

\section{Introduction}

Like all invasive procedures, invasive coronary interventions also present some risks to the patient. The main reason prolonging hospital stay maximally and the most frequent cause of morbidity in percutaneous coronary intervention (PCI) is complications due to vascular interventions. Hemorrhage, hematoma, distal emboli, pseudo-aneurysm and arterial thrombosis are the most important vascular complications observed [1]. Studies show local vascular complications following PCI vary between $2.9 \%-65.0 \%$ [2-8].

Vascular complications developing after PCI prolong hospital stay of patients, lead to additional diagnostic and therapeutic procedures, thus, give rise to additional work load and cost, and most of all, they increase mortality $[3,4,9]$.

Haemostatic control following PCI is traditionally made by manual compression. But nowadays, systems using more sutures for closing vascular entry area, and systems applying clips and forming plug are the methods of choice. Moreover, as a method of maintaining haemostasis following intervention, sand bags are still being used in our country. However studies report that sand bag application is less tolerable by the patients, and it causes pain and discomfort rather than the effect of pressure [10-13]. And because pain is related with anxiety, fatigue, restlessness and displeasure in patients, it affects compliance to treatment and recovery process adversely [14]. Low back pain score, that can be observed following PCI and is reported as an important problem, vary between 3.8-7.0 in studies [15-17]. 
Another method used for maintaining haemostasis and hematoma control in general is cold application. In a randomized controlled trial made by King et al. [18], in which ice and sand bags were applied to intervention area in patients developing hematoma at femoral region following PCI, it was determined that ice application decreased hematoma development significantly, and increased patient comfort and satisfaction. When literature was reviewed, it was seen that there are quite different methods used for providing and maintaining haemostasis but ice application is not used for this purpose.

Cold application increases coagulation by decreasing the flow rate of blood via arteriolar vasoconstriction and increasing its viscosity. Thus, increase in the coagulation, and decrease in capillary permeability and metabolic needs facilitate control of bleeding at trauma site. And so, it can reduce development of ecchymosis and hematoma [19].

In patient care, following diagnostic and interventional cardiology procedures the primary role of nurse is prevention of local vascular complications and provision of patient comfort [6,20,21]. Control of both local vascular complications and pain, which is an experience as old as human history, reduce patient's hospital stay and treatment costs [21]. Prevention of complications is also important for providing collaboration and compliance to the process, and so accelerating recovery. Because all these factors improve patient satisfaction, and patient satisfaction improves general health status, the quality of nursing service increases.

Although radial route is favored for PCI in recent years due to its advantages, in our country, femoral route is still frequently used, sand bag is applied to provide haemostasis.

\section{The Study Hypothesis}

$\mathbf{H}_{0}$ : In individuals who had PCI, ice application to femoral region is not effective in reducing local vascular complications.

$\mathbf{H}_{1}$ : In individuals who had PCI, ice application to femoral region is effective in reducing local vascular complications.

\section{Material and Method}

This study is an experimental study, aimed to investigate the effect of ice bag application to femoral region on local vascular complications and on lower back pain, following PCI. The research was conducted between September of 2013 and May of 2014 in the Cardiac Hospital affiliated with the Health Application and Research Center of Erciyes University. The study was conducted with 298 patients (104 in ice-bag group, 100 in sandbag group and 94 in no application group) who were eligible for the study criteria.

The research was conducted on patients, who approved for study participation and were able to speak and understand Turkish, who were older than 18 years old, who underwent a femoral intervention and were inserted a single catheter on their femoral region, who had proper time and place orientation with no psychiatric disorders nor any problems with seeing or hearing, who had no cold allergy, who had no active bleeding before the catheter withdrawal. The exclusion criteria for participants were as follows: having known bleeding disorders, developed active bleeding at catheter insertion site before sheath removal, experiencing lower back pain before the procedure, developed any complications during the procedure, use of glycoprotein IIb/IIIa inhibitors, systolic blood pressure greater than $190 \mathrm{mmHg}$ or diastolic blood pressure greater than 110 $\mathrm{mmHg}$.Data in this study were gathered via patient identification form, post-intervention vascular complication surveillance form and visual analog scale (VAS).

Patient Identification Form: Patient identification form, which was designed by the author by reviewing related literature, consists of descriptive properties of individuals, laboratory results, vital signs and information regarding coronary intervention. Patient identification form was filled by the author and a surveyor trained by the author, by face to face consultation with the individuals and by examining patient files.

Vascular Complications Form: Post-intervention vascular complications form was composed by the author by reviewing the literature. Types of possible vascular complications that can be seen in individuals following intervention were present in the form. The complications in the form (hemorrhage, hematoma, ecchymosis, pseudo-aneurysm, pulsatile mass and other developed complications) were scored as "present" or "absent", and within complications that were present, hemorrhage and hematoma were scored again as "major" and "minor". Hemorrhage and hematoma status of individuals were determined visually and by manual examination.

In the presence of hematoma, the circumference of hematoma was marked with a water-resistant pen and size of the hematoma was measured via a measuring tape. Hematomas over $5 \mathrm{~cm}$ were recorded as major hematoma, and hematomas less than $5 \mathrm{~cm}$ were recorded as minor hematoma. Hemorrhages that were estimated less than $100 \mathrm{~mL}$ were recorded as minor hemorrhage, and hemorrhages estimated equal or larger than $100 \mathrm{~mL}$ (hemorrhage penetrating bandages) were recorded as major hemorrhage. Ecchymosis was determined as bluepurple discoloration of skin in physical examination, following bleeding into subcutaneous tissue, whereas for pseudo-aneurysms ultrasonography reports were used. 
Complication surveillance form was started to be filled right after the intervention, and then at 15 minute intervals in the first hour, at half hour interval at the second hour and then hourly later on, by observing individual's femoral region and recording the evaluation results onto the form by the author and surveyor. A week after individual's discharge from hospital, they were called by phone by the author and consulted about whether any complications occurred; according to individual's statement, complications were recorded on the form. Local vascular complications in femoral region that developed during individual's hospital stay were evaluated as "complications developed at first follow-up"; complications that individuals stated on the phone when they were called on 7th day after their discharge were evaluated as "complications developed at second follow-up"; complications that developed both in first and second follow-up were evaluated as "complications developed in total".

Following the intervention, catheter placed in the femoral region was retrieved by cardiology resident in each group, and manual pressure was applied to the operated region by the same resident until haemostasis was ensured; duration of pressure application was recorded in the form by the author and surveyor. Following achievement of haemostasis, operated femoral region was covered with compression dressing (prepared with 2 compression bandages with $5 \mathrm{~cm}$ width and 100 meter length together with plasters) and individuals were monitored in supine position for 6 hours.

\section{Ice Bag Group}

In ice bag applied group, after the operated femoral region was covered with compression dressing, ice bag was applied for 20 minutes with 10 minute intervals during 2 hours, and individuals were monitored for 6 hours in supine position. At the application of ice-bag, an ice-bag was used that had a size of $23 \mathrm{~cm}$, reusable, with a curly design that provided well-fitting to body, a waterproof ice chamber with a feature of thermal insulation

\section{Sandbag Group}

The sandbag group received the routine care; including 6-hour complete bed rest in supine position with the affected leg straight and immobilized, with a sandbag (weighing $4.5 \mathrm{~kg}$ ) on the puncture site.

\section{No Application Group}

After the operated femoral region was covered with compression dressing, no manipulation was done in no application group; femoral region was left empty and individuals were monitored for 6 hours in supine position. In all the three study groups, no intervention was made on routine treatments of the individuals.

All patients were assessed for low back-pain at regular time points. These points included the time immediately after coming to the post catheterization unit (T1), at $2 \mathrm{~h}$ (T2), 4h (T3), 6h after cardiac catheterization (T4) and finally the next morning at 08:00 A.M. (T5).

\section{Ethical Considerations}

Before starting the investigation, the necessary written permissions were obtained both from the Erciyes University Clinical Studies Ethical Committee and from the Erciyes University Cardiac Hospital. At first, the aim of the study was explained and the relevant information of the investigation was given to the participants and their written informed consent forms were obtained.

\section{Statistical Analyses}

For comparison of variables according to time, one way analysis of variance with repeated measures, and Friedman analysis were used; whereas for comparison of groups according to time, area under curve formula was used. As for multiple comparison tests, parametric Tukey test and non-parametric Dunn test were used. Two way and three way analysis of variance were used for comparison of variables with interaction.As for descriptive statistics, frequency tables, mean \pm standard deviation, median percentile values $(25 \%-75 \%)$ were calculated. Chi-square test was used for comparison of categorical variables.

\section{Results}

It was found that complication developed in $41.2 \%$ of individuals in total during follow-up. It was determined that complication developed in $27.9 \%$ of the individuals in ice bag applied group, in $42.0 \%$ of individuals in sand bag applied group, and in $55.3 \%$ of individuals in no application group; and it was determined that difference between the groups with regard to complication development is significant. When types of complications were evaluated, the highest numbers of hemorrhage $(11.7 \%)$ and ecchymosis $(51 \%)$ were observed in no application group; the highest number of hematoma (14\%) was seen in sand bag applied group. Major hemorrhages developed in similar rates in all three groups; and none of them was fatal. There was 
The Effect of Ice-Bag Appiled to Femoral Region of Individuals with Percutaneous Coronary ..

pseudo-aneurysm development requiring surgery in $2.1 \%$ of the individuals in no application group, whereas there was none in the other two groups (Table 2).

At first follow-up, complication developed in $17.4 \%$ of individuals. Complication developed in $11.5 \%$ of ice bag applied group, $21.0 \%$ of sand bag applied group, and 20.2\% of no application group (Table 3).

Within complications, hemorrhage was most seen in no application group $(11.7 \%)$; hematoma $(14.0 \%)$ and ecchymosis $(18.0 \%)$ were most seen in sand bag applied group. Major hemorrhages developed in similar rates in all three groups; and none of them were fatal. There was pseudo-aneurysm development requiring surgery in $1.0 \%$ of the individuals in no application group, whereas there was none in the other two groups (Table 3).

At second follow-up, complication developed in $31.5 \%$ of individuals. Complication developed in $47.9 \%$ of no application group, $29.0 \%$ of sand bag applied group, and $19.2 \%$ of ice application group (Table 4).

No hemorrhage was seen at second follow-up in any of the groups. The highest numbers of hematoma $(6.3 \%)$ and ecchymosis $(47.8 \%)$ developed in no application group. There was pseudo-aneurysm development requiring surgery in $1.0 \%$ of the individuals in no application group, whereas there was none in the other two groups (Table 4).

It was determined that there was a highly significant difference between VAS ordinal scores of individuals according to time of observation between ice bag applied group, sand bag applied group and no application group. In further analysis, it was found that VAS ordinal scores of individuals in ice bag applied group increased gradually (VAS1 $=2.5$ whereas $\mathrm{VAS}=3.4$ ) and the difference between them was statistically significant except for VAS1-VAS2 and VAS4-VAS5 (Table 6).

It was determined that VAS ordinal scores of individuals in no application group increased gradually (VAS1=2.3 whereas VAS=3.3) and the difference between them was statistically significant except for VAS3VAS4, VAS3-VAS5 and VAS4-VAS5 (Table 6).

It was found that VAS ordinal scores of individuals in sand bag applied group increased gradually (VAS1=1.5 whereas VAS=4.1) and the difference between them was statistically significant (Table 6).

In Figure 1, where VAS scores of groups are plotted against follow-up time, it was found that there is no difference between individuals in ice bag applied group and no application group with regard to VAS scores, and that there is highly significant difference between ice bag applied group and sand bag applied group, and between sand bag applied group and no application group (Figure 1).

\section{Discussion}

In percutaneous coronary interventions femoral route is generally preferred in our country due to ease of practice and high success rates. However, local vascular complications related to catheter placement in femoral region constitute one of the main reasons of procedure-related morbidity [3,4,22]. In our study, complication developed in $17.4 \%$ of individuals in all three groups at first follow-up in hospital, in $31.5 \%$ at second follow-up one week after discharge, and $41.2 \%$ in total.

When studies were reviewed with regard to complications developing in hospital, it was observed that there were studies which had results of complication rates close to ours (16.5\%-17\%), less than ours (2.9\%), and more than ours $(35.7 \%-65 \%)$ [2-8]. These differences between the results of studies are thought to be originating from differences in methods for providing and maintaining haemostasis, mobilization time, intervention characteristics, and methodological differences like evaluation of complications and selection criteria.

It was observed that the most frequent local vascular compression following PCI in past studies was ecchymosis, followed by hematoma, hemorrhage and pseudo-aneurysm [12,23-25]. It was observed that the order of most frequent complications in our study at first and second follow-up and in total are consistent with the reported findings. It was determined that the most frequent complication at first and second follow-up and in total was ecchymosis (13.4\%-35.0\%-37.9\% respectively), however the least number of ecchymosis at all followups were detected in ice bag applied group. In past studies the rates of ecchymosis which were questioned at different times after patients' discharge vary between 35.0\% - 68.6\% [25-28]. Although ecchymosis is observed frequently as shown in the study results, it is not accepted as major complication. However it is regarded as a complication raising anxiety and stress in patients, affecting life quality and mobilization. Also its importance should not be ignored, as ecchymosis developing after PCI can be evaluated as minor hemorrhage complication [28].

Nearly half of the hemorrhage occurring in patients after PCI is at arterial entry site; its severity can vary from insignificant hematoma to mortal retroperitoneal hemorrhages [29]. In our study hemorrhage complication was least seen in ice bag applied group (3.8\%), followed by sand bag applied group (8\%) and no application group (11.7\%). Major hemorrhages that develop after PCI are classified as serious complications as they increase the risk of ischemic event development [30]. In our study major hemorrhage developed in $2.3 \%$ of individuals, and it was observed that major hemorrhages in each three groups were around rates of $2 \%$ and none of them were fatal. 
The least number of complications at follow-ups occurred in ice bag applied group, and differences between the groups were found statistically significant. Moreover, in ice bag applied group hemorrhage, hematoma and ecchymosis development rates were lower than in the other groups and also there was no complication requiring surgical intervention in this group. Ice application reduces blood flow and capillary permeability near application site, controls bleeding and facilitates coagulation by increasing viscosity of blood. Therefore bleeding, hematoma and ecchymosis occurs less in ice-applied tissue [19]. In studies involving different topics related with ice application, it was determined that ice application has positive impacts on ecchymosis and hematoma development $[31,32]$. There are not any studies in literature in which ice application is used for prevention of local vascular complications following PCI, although there is only one study investigating the effect of ice application on complication that developed before. In that single-blind randomized controlled trial, patients developing hematoma following PCI were grouped into two for sand bag application and ice bag application; it was found that hematoma were significantly reduced in ice application group [18].

In our study complication rates were similar in sand bag applied group (21.0\%) and no application group $(20.2 \%)$ at first follow-up, but developed less in ice bag applied group $(11.5 \%)$. Highest number of hemorrhage at first follow-up was observed in no application group, and highest number of hematoma and ecchymosis developed in sand bag applied group. In the study made by Lehmann et al. the group in which no application was made was compared to the group with sand bag application; both hemorrhage and hematoma were observed more in sand bag applied group [12]. Because there are no studies in literature made with ice application, a comparison could not be made.

It was found that in sand bag applied group at first follow-up, $8.0 \%$ of patients developed hemorrhage, $18.0 \%$ developed hematoma, and none of them developed pseudo-aneurysm. In a study made by Farmanbar et al.33, haemostasis was achieved by manual pressure application following retrieval of femoral catheter in one group of patients, and later, two sand bags, $2.5 \mathrm{~kg}$ each, were applied. One of the sand bags was taken away after 1 hour, while the other was kept until patient's mobilization; patients were mobilized after 6 hours. It was determined that hematoma developed in $6.6 \%$ of patients in this group.

In one group in Armendaris et al's study [34], haemostasis was achieved with mechanical pressure following retrieval of the femoral catheter, and a $2 \mathrm{~kg}$ sandbag was applied to femoral region for two hours; it was found that local ecchymosis developed in $17.1 \%$ of patients. Our findings are consistent with the results of other studies. In our study it was found that at first follow-up hemorrhage developed in $11.7 \%$ of patients, ecchymosis in $15.9 \%$, and pseudo-aneurysm in $1.0 \%$ in no application group. In Botti et al's study [27], ecchymosis was detected in $14.5 \%$ of patients, and in Sulzbach-Hoke et al's study [6] pseudo-aneurysm was detected in $1.9 \%$ of patients. In a study by Jones et al. [26] hemorrhage was seen in $10.0 \%$ of patients, hematoma in $12.0 \%$, and ecchymosis in $12.0 \%$. Our findings are consistent with the results of other studies.

In our study at second follow-up the least number of complications occurred in ice bag applied group and the differences between the groups were statistically significant. There were no hemorrhages at second follow-up in all three groups; and as opposed to other groups there was pseudo-aneurysm that required surgery in $1.0 \%$ of patients in no application group. While Farmanbar et al. [33] reported that there were no hemorrhages or pseudo-aneurysms 30 days after discharge, Jones et al. [26] found ecchymosis in $20.0 \%$ of patients, hematoma in $6.0 \%$ and hemorrhage in $1.0 \%$ five days after discharge. The studies were generally limited to complications that developed during hospital stay; in most cases complications that could develop after patient's discharge were not investigated [2,6].

Because obtaining information about complications that can develop after patient's discharge can be instructive on planning patient education by cardiology nurses, it is important with regard to training and consulting patients adequately in hospital. Patients should be informed about what is awaiting them, possible complication development during recovery process and how they can get appropriate support [7]. Thus, patient's anxiety can diminish and compliance to treatment can be enhanced. Also, patient satisfaction can be improved by offering early diagnosis and treatment.

Uncontrollable factors like patient age, sex, concomitant diseases etc. play role in complication development after PCI; in Sabo et al's study [25] it is noted that patient discomfort and distress can play part in development of complications. Researchers reported that the most frequent complaint of patients following PCI was lower back pain and most of the patients received pharmacological treatment for this $[21,35,36]$. Pain increases patient fatigue and dissatisfaction as well as causing hypertension and tachycardia via activation of autonomous nervous system, increasing cardiac load and myocardial oxygen consumption, leading up to arrhythmias, ischemia, acute cardiac failure and myocardial infarction in patients with coronary heart disease [37,38]. Although it is advised that patients stay in bed for a long time after PCI performed via femoral route to prevent development of complications, McCabe et al. [39] denote that this practice is not evidence-based but traditional. Recent studies indicate early mobilization does not affect complication development adversely, but rather increases patient comfort $[5,10,11,40,41]$. It is stated that extended bed rest in supine position is hard and discomforting for the patient $[10,11,15,36]$. Studies related to early mobilization showed that in patients who 
The Effect of Ice-Bag Appiled to Femoral Region of Individuals with Percutaneous Coronary ..

had PCI, extended bed rest increases pain and need for analgesics [5,17,42]. In our study it was observed that in all three groups low back pain scores increased in parallel to the time spent in bed.

In studies using sand bag application for maintaining haemostasis, it was determined that sand bag application was not effective for preventing vascular compression, moreover it increased patient discomfort and was less tolerable by patients [10-13]. Although sand bag application reduces bed rest, time spent in hospital and hospital costs, it increases patient discomfort and dissatisfaction. In a study by Y1lmaz [13] in which he compared groups of patients which were positioned with applying sand bags of different weights, not positioned and no application was done, it was determined that VAS scores increased in all groups with time, and highest VAS scores were in patient group lying supine with sand bag application. In our study, it was found that the highest VAS scores were in individuals in sand bag applied group, and differences between groups were statistically significant. There was no significant difference between ice bag applied group and no application group, but since complication rates in no application group were higher and a complication that required surgery developed in this group, we think the most effective one of these three practices is ice bag application. The main purpose in nursing practices is prevention of possible complications, enabling early mobilization of patient, reducing the pain, providing contribution to returning active life and thus, increasing life quality [6,21]. Manipulations aiming prevention of complications developing after PCI are supported with studies, but we observe that traditional practices predominate in clinics, and evidences are not endorsed in routine practices. For best patient care, caring nurses must be able to manage the intervention area well after PCI.

\section{Conclusion}

As a result; it is determined that vascular complications observed after PCI constitute a problem either in hospital and following discharge; there is an increase in individual's VAS score with time in parallel to extended bed rest following PCI; ice bag application following PCI reduces vascular complications, decreases lower back pain score compared to sand bag application, is easy to apply and economical, is an application that can easily be performed by nurses after PCI. In conclusion, ice bag application is considered a superior method compared to sand bag application with regards to decreasing complication rates and providing patient comfort. Ice bag application is especially a safe method in low risk patients who had coronary angiography and have no other clinical issues regarding coagulopathies. More detailed studies are needed to test the effectiveness of ice bag application in high risk patients.

\section{Limitations and Future Research}

This study was performed in a local Cardiac Hospital in Kayseri; therefore, its results may not represent the general practice. To support these findings, a similar investigation shall be performed as a multicentric study conducted in different regions.

\section{References}

[1]. Kıraç S. The role of advanced cardiac imaging in coronary artery disease Anadolu Kardiol Journal 2008; 8(suppl 1): 1-4

[2]. Piper WD, Malenka DJ, Ryan TJ Jr, et al. Predicting vascular complications in percutaneous coronary interventions. Am Heart J 2003; 145(6): 1022-1029

[3]. Kuchulakanti PK, Satler LF, Suddath WO, et al. Vascular complications following coronary intervention correlate with long-term cardiac events. Catheter Cardiovasc Interv 2004; 62(2): 181-185

[4]. Pracyk JB, Wall TC, Longabaugh JB, et al. A randomized trial of vascular hemostasis techniques to reduce femoral vascular complications after coronary intervention. Am J Cardiol 1998; 81: 970-976

[5]. Pollard SD, Munks K, Wales C, et al. Position and mobilisation post-angiography study (PAMPAS): a comparison of 4.5 hours and 2.5 hours bed rest. Heart 2003; 89(4): 447-448

[6]. Sulzbach-Hoke LM, Ratcliffe SJ, Kimmel SE, Kolansky DM, Polomano R. Predictors of complications following sheath removal with percutaneous coronary intervention. J Cardiovasc Nurs 2010; 25(3): E1-E8

[7]. Higgins M, Theobald K, Peters J. Vascular access and cardiac complications after PCI: In-and out- of hospital outcome issues. British Journal of Cardiac Nursing 2008; 3(3): 111-116

[8]. Dumont C, Keeling A, Bourguignon C, Sarembock IJ, Turner M. Predictors of vascular complications post diagnostic cardiac catheterization and percutaneous coronary interventions. Dimens Crit Care Nurs 2006; 25(3): 137-142

[9]. Kugelmass AD, Cohen DJ, Brown PP, et al. Hospital resources consumed in treating complications associated with percutaneous coronary interventions. Am J Cardiol 2006; 97: 322-327

[10]. Rezaei-Adaryani M, Ahmadi F, Mohamadi E, Asghari-Jafarabadi M. The effect of three positioning methods on patient outcomes after cardiac catheterization. J Adv Nurs 2009; 65(2): 417-424

[11]. Rezaei-Adaryani M, Ahmadi F, Asghari-Jafarabadi M. The effect of changing position and early ambulation after cardiac catheterization on patients' outcomes: a single-blind randomized controlled trial. Int J Nurs Stud 2009; 46(8): 1047-1053

[12]. Lehmann KG, Ferris ST, Heath-Lange SJ. Maintenance of hemostasis after invasive cardiac procedures: implications for outpatient catheterization. J Am Coll Cardiol 1997; 30: 444-451

[13]. Yilmaz E. The study of the effects of application local weight on the patient and changing the position of the patient on vascular complication and back pain over the patients who have cardiac invasive procedure, $\mathrm{PhD}$ Thesis, Ege University Graduate School of Health Sciences, İzmir 2004: 106-107

[14]. Çöçelli LP, Bacaksız BD, Ovayolu N. The role of the nurse in the treatment of pain. Gaziantep Medical Journal 2008; 14: 53-58

[15]. Fowlow B, Price P, Fung T. Ambulation after sheath removal: a comparison of 6 and 8 hours of bedrest after sheath removal in patients following a PTCA procedure. Heart and Lung 1995; 24: 28-37 
[16]. Gulanick M, Bliley A, Perino B, Keough V. Patients' responses to the angioplasty experience: a qualitative study. Am J Crit Care 1997; 6(1): 25-32

[17]. Wang SL, Redeker NS, Moreyra AE, Diamond MR. Comparison of comfort and local complications after cardiac catheterization. Clin Nurs Res 2001; 10(1): 29-39

[18]. King NA, Philpott SJ, Leary A. A randomized controlled trial assessing the use of compression versus vasoconstriction in the treatment of femoral hematoma occurring after percutaneous coronary intervention. Heart \& Lung 2008; 37(3): 205-210

[19]. Karunakara RG, Lephart SM, Pincivero DM. Changes in forearm blood flow during single and intermittent cold application. J Orthop Sports Phys Ther. 1999; 29(3): 177-180

[20]. Rolley JX. Nursing care practices following a percutaneous coronary intervention. results of a survey of Australian and New Zealand cardiovascular nurses. J Cardiovasc Nurs 2010; 25(1): 75-84

[21]. Leeper B. Nursing outcomes: percutaneous coronary interventions. J Cardiovasc Nurs 2004; 19(5): 346-53

[22]. Parkosewich JA. Assessment of cardiovascular function. In: Smelt-zer SC, Bare BG, Hinkle JL, Cheever KH, (eds), Brunner and Suddarth's textbook of medical surgical nursing. 11th ed. Philadelphia, Lippincott Williams and Wilkins, 2007; 780-821Schickel SI, Adkisson P, Miracle V, Cronin SN. Achieving femoral artery hemostasis after cardiac catheterization: a comparison of methods. Am J Crit Care 1999; 8(6): 406-9

[23]. Behan MW, Large JK, Patel NR, Lloyd GW, Sulke AN. A randomised controlled trial comparing the routine use of an Angio-Seal STS device strategy with conventional femoral haemostasis methods in a district general hospital. Int J Clin Pract 2007; 61(3): 367372

[24]. Chlan LL, Sabo J, Savik K. Effects of three groin compression methods on patient discomfort, distress, and vascular complications following a percutaneous coronary intervention procedure. Nurs Res 2005; 54(6): 391-8

[25]. Sabo J, Chlan LL, Savik K. Relationships among patient characteristics, comorbidities, and vascular complications postpercutaneous coronary intervention. Heart Lung 2008; 37(3): 190-195

[26]. Jones T, McCutcheon H. A randomized controlled trial comparing the use of manual versus mechanical compression to obtain coronary angiography. Intensive Crit Care Nurs 2003; 19(1): 11-20

[27]. Botti M, Williamson B, Steen K, McTaggart J, Reid E. The effect of pressure bandaging on complications and comfort in patients undergoing coronary angiography: a multicenter randomized trial. Heart Lung 1998; 27(6): 360-373

[28]. Cosman TL, Arthur HM, Natarajan MK. Prevalence of bruising at the vascular access site one week after elective cardiac catheterisation or percutaneous coronary intervention. J Clin Nurs 2011;20:1349-1356

[29]. Kinnaird TD, Stabile E, Mintz GS, et al. Incidence, predictors, and prognostic implications of bleeding and blood transfusion following percutaneous coronary interventions. Am J Cardiol 2003; 92(8): 930-935

[30]. Steg PG, Huber K, Andreotti F, et al. Bleeding in acute coronary syndromes and percutaneous coronary interventions: position paper by the Working Group on Thrombosis of the European Society of Cardiology. Eur Heart J 2011; 32(15): 1854-64

[31]. Kuzu N, Uçar H. The effect of cold on the occurrence of bruising, haematoma and pain at the injection site in subcutaneous low molecular weight heparin, Int J Nurs Stud 2001; 38: 51-59

[32]. Kucukguclu O, Okumuș H. The Effects of The Application of The Ice to The Injection Site, on The Patients Who Are Administered Anticoagulant Therapy, DEUHYO ED 2010, 3(4), 182-186

[33]. Farmanbar R, Chinikar M, Gozalian M, et al. The Effect of Post Coronary Angiography Bed-Rest Time onVascular Complications. J Teh Univ Heart Ctr 2008; 4: 225-228

[34]. Armendaris MK, Azzolin KO, Alves FJMS, Ritter SG, Moraes MAP. Incidence of vascular complications in patients submitted to percutaneous transluminal coronary angioplasty by transradial and transfemoral arterial approach. Acta paul. enferm 2008; 21(1): $107-111$

[35]. Gulanick M, Bliley A, Perino B, Keough V. Patients' responses to the angioplasty experience: a qualitative study. Am J Crit Care 1997; 6: 25-32

[36]. Vlasic W, Almond D, Massel D. Reducing bedrest following arterial puncture for coronary interventional procedures-impact on vascular complications: the BAC trial. J Invasive Cardiol. 2001; 13: 788-792

[37]. Louville AB, Legroux-Gerot I, Cortet B, et al. Pain management in a rheumatology department: a satisfaction survey. Joint Bone Spine 2003; 70: 362-366

[38]. Morton PG, Fontaine DK. Critical Care Nursing a Holistic Approach, 8th edn. Lippincott Williams \& Wilkins, Philadelphia, 2005: 393-421

[39]. McCabe P, McPherson L, Lohse C, Weaver AL. Evaluation of nursing care after diagnostic coronary angiography. Am J Crit Care 2001; 10(5): 330-340

[40]. Doyle BJ, Konz BA, Lennon RJ, Bresnahan JF, Rihal CS, Ting HH. Ambulation 1 hour after diagnostic cardiac catheterization: a prospective study of 1009 procedures. Mayo Clin Proc 2006; 81: 1537-1540

[41]. Walker S, Jen C, McCosker F, Cleary S. Comparison of Complications in Percutaneous Coronary Intervention Patients Mobilized at 3, 4, and 6 Hours After Femoral Arterial Sheath Removal. J Cardiovasc Nurs 2008; 23(5): 407-413

[42]. Nikolsky E, Mehran R, Halkin A, et al. Vascular complications associated with arteriotomy closure devices in patients undergoing percutaneous coronary procedures: a meta-analysis. J Am Coll Cardiol 2004; 44: 1200-1209 
The Effect of Ice-Bag Appiled to Femoral Region of Individuals with Percutaneous Coronary..

Table 1. Demographic and clinical characteristics of the patients $(n=298)$

\begin{tabular}{|c|c|c|c|c|}
\hline Variable & $\begin{array}{c}\text { Ice-bag Group } \\
(n=104)\end{array}$ & $\begin{array}{c}\text { Sandbag Group } \\
(n=100)\end{array}$ & $\begin{array}{l}\text { No Application } \\
\text { Group }(n=94)\end{array}$ & $p$ \\
\hline \multicolumn{5}{|l|}{ Age groups (years) } \\
\hline 50 and younger & 21.2 & 17.0 & 29.9 & \multirow{3}{*}{0.205} \\
\hline $51-70$ & 49.0 & 51.0 & 48.9 & \\
\hline 71 and older & 29.8 & 32.0 & 21.2 & \\
\hline Age (years \pm SD) & $62.2 \pm 12.3$ & $57.5 \pm 13.4$ & $63.3 \pm 11.5$ & \\
\hline Gender Female & 36.5 & 38.0 & 44.7 & 0.466 \\
\hline BMI & $28.7 \pm 5.2$ & $29.2 \pm 5.5$ & $29.1 \pm 5.0$ & 0.705 \\
\hline Cigarette smoking & 48.1 & 45.0 & 46.8 & 0.590 \\
\hline \multicolumn{5}{|l|}{ Comorbidity } \\
\hline Diabetes & 34.6 & 42.0 & 36.2 & 0.521 \\
\hline Hypertension & 54.8 & 56.0 & 48.9 & 0.575 \\
\hline Hyperlipidemia & 45.2 & 44.0 & 44.7 & 0.985 \\
\hline Use of anticoagulants & 56.7 & 53.4 & 55.3 & 0.412 \\
\hline Time to hemostasis (min) & $9.1 \pm 3.7$ & $10.4 \pm 5.8$ & $8.3 \pm 4.8$ & 0.098 \\
\hline PLT & $256.4 \pm 84.9$ & $273.2 \pm 92.6$ & $258.5 \pm 86.0$ & 0.348 \\
\hline INR & $1.2 \pm 0.4$ & $1.2 \pm 0.3$ & $1.1 \pm 0.3$ & 0.172 \\
\hline PT (second) & $13.2 \pm 4.6$ & $13.6 \pm 3.5$ & $12.4 \pm 3.1$ & 0.127 \\
\hline Heart rate (b/min) & $78.5 \pm 13.0$ & $82.5 \pm 13.5$ & $79.0 \pm 12.1$ & 0.070 \\
\hline
\end{tabular}

Table 2. Presence of vascular complications at in the total follow-up

\begin{tabular}{|c|c|c|c|c|c|c|c|}
\hline \multirow{3}{*}{ Vascular Complications * } & \multicolumn{6}{|c|}{ Groups } & \multirow{3}{*}{$p$} \\
\hline & \multicolumn{2}{|c|}{$\begin{array}{c}\text { Ice-bag Group } \\
n=104\end{array}$} & \multicolumn{2}{|c|}{$\begin{array}{c}\text { Sandbag Group } \\
n=100\end{array}$} & \multicolumn{2}{|c|}{$\begin{array}{c}\text { No Application Group } \\
n=94\end{array}$} & \\
\hline & $\mathbf{n}$ & $\%$ & $\mathbf{n}$ & $\%$ & $\mathbf{n}$ & $\%$ & \\
\hline No & 75 & 72.1 & 58 & 58.0 & 42 & 44.7 & \\
\hline \multicolumn{8}{|l|}{ Types of Complications** } \\
\hline Hemorrhage & 4 & 3.8 & 8 & 8.0 & 11 & 11.7 & \\
\hline Minor hemorrhage & 1 & 0.9 & 6 & 6.0 & 9 & 9.6 & \\
\hline Hematoma & 9 & 8.6 & 14 & 14.0 & 9 & 9.5 & \\
\hline Major hematoma & 3 & 2.8 & 6 & 6.0 & 2 & 2.1 & \\
\hline Minor hematoma & 6 & 5.8 & 8 & 8.0 & 7 & 7.4 & \\
\hline Ecchymosis**** & 25 & 24.0 & 40 & 40.0 & 48 & 51.0 & \\
\hline Pseudo-aneurysm & 0 & 0.0 & 0 & 0.0 & 2 & 2.1 & \\
\hline
\end{tabular}

* Total complications $41.2 \%$ ** More than one complication *** Total ecchymosis $37.9 \%$

Table 3. Presence of vascular complications at in the first follow-up

\begin{tabular}{|c|c|c|c|c|c|c|c|}
\hline \multirow[t]{3}{*}{ Vascular Complications * } & \multicolumn{6}{|c|}{ Groups } & \multirow{3}{*}{$p$} \\
\hline & \multicolumn{2}{|c|}{$\begin{array}{c}\text { Ice-bag Group } \\
n=104\end{array}$} & \multicolumn{2}{|c|}{$\begin{array}{c}\text { Sandbag Group } \\
n=100\end{array}$} & \multicolumn{2}{|c|}{$\begin{array}{c}\text { No Application Group } \\
n=94\end{array}$} & \\
\hline & $\mathbf{n}$ & $\%$ & $\mathbf{n}$ & $\%$ & $\mathbf{n}$ & $\%$ & \\
\hline Yes & 12 & 11.5 & 21 & 21.0 & 19 & 20.2 & 0.143 \\
\hline No & 92 & 88.5 & 79 & 79.0 & 75 & 79.8 & \\
\hline \multicolumn{8}{|l|}{ Types of Complications*** } \\
\hline Hemorrhage & 4 & 3.8 & 8 & 8.0 & 11 & 11.7 & \\
\hline Major hemorrhage & 3 & 2.9 & 2 & 2.0 & 2 & 2.1 & \\
\hline Minor hemorrhage & 1 & 0.9 & 6 & 6.0 & 9 & 9.6 & \\
\hline Hematoma & 7 & 6.7 & 12 & 12.0 & 6 & 6.3 & \\
\hline Major hematoma & 3 & 2.9 & 5 & 5.0 & 2 & 2.1 & \\
\hline Minor hematoma & 4 & 3.8 & 7 & 7.0 & 4 & 4.2 & \\
\hline Ecchymosis*** & 7 & 6.7 & 18 & 18.0 & 15 & 15.9 & \\
\hline Pseudo-aneurysm & 0 & 0.0 & 0 & 0.0 & 1 & 1.0 & \\
\hline
\end{tabular}

* Total complications $17.4 \% * *$ More than one complication *** Total ecchymosis $13.4 \%$ 
The Effect of Ice-Bag Appiled to Femoral Region of Individuals with Percutaneous Coronary..

Table 4. Presence of vascular complications at in the second follow-up

\begin{tabular}{|c|c|c|c|c|c|c|c|}
\hline \multirow[t]{3}{*}{ Vascular Complications * } & \multicolumn{6}{|c|}{ Groups } & \multirow{3}{*}{$p$} \\
\hline & \multicolumn{2}{|c|}{$\begin{array}{c}\text { Ice-bag Group } \\
n=104\end{array}$} & \multicolumn{2}{|c|}{$\begin{array}{c}\text { Sandbag Group } \\
n=100\end{array}$} & \multicolumn{2}{|c|}{$\begin{array}{c}\text { No Application Group } \\
n=94\end{array}$} & \\
\hline & $\mathbf{n}$ & $\%$ & $\mathbf{n}$ & $\%$ & $\mathbf{n}$ & $\%$ & \\
\hline Yes & 20 & 19.2 & 29 & 29.0 & 45 & 47.9 & $<0.001$ \\
\hline No & 84 & 80.8 & 71 & 71.0 & 49 & 52.1 & \\
\hline \multicolumn{8}{|l|}{ Types of Complications** } \\
\hline Hemorrhage & 0 & 0.0 & 0 & 0.0 & 0 & 0.0 & \\
\hline HematomaHematoma & 2 & 1.9 & 2 & 2.0 & 6 & 6.3 & \\
\hline Major hematoma & 0 & 0.0 & 1 & 1.0 & 1 & 1.0 & \\
\hline Minor hematoma & 2 & 1.9 & 1 & 1.0 & 5 & 5.3 & \\
\hline Ecchymosis*** & 20 & 19.2 & 29 & 29.0 & 45 & 47.8 & \\
\hline Pseudo-aneurysm & 0 & 0.0 & 0 & 0.0 & 1 & 1.0 & \\
\hline
\end{tabular}

* Total complications $31.5 \% \quad * *$ More than one complication *** Total ecchymosis $35.0 \%$

Table 5. Group differences in back pain at each of the five assessment times (T1-T5)

\begin{tabular}{|l|c|}
\hline Pain level after procedure & $\boldsymbol{p}$ \\
\hline Immediately after procedure (T1) & $>0.05$ \\
2 hours after procedure (T2) & $<\mathbf{0 . 0 5}$ \\
4 hours after procedure (T3) & $<\mathbf{0 . 0 5}$ \\
6 hours after procedure (T4) & $<\mathbf{0 . 0 5}$ \\
Next morning (T5) & $<\mathbf{0 . 0 5}$ \\
\hline
\end{tabular}

Table 6. VAS ranking score changes for three groups at the five time periods

\begin{tabular}{|l|c|c|c|}
\hline Time & $\begin{array}{c}\text { Ice-bag Group } \\
\boldsymbol{n = 1 0 4}\end{array}$ & $\begin{array}{c}\text { Sandbag Group } \\
\boldsymbol{n}=\mathbf{1 0 0}\end{array}$ & $\begin{array}{c}\text { No Application Group } \\
\boldsymbol{n}=\mathbf{9 4}\end{array}$ \\
\hline T1 & $2.5^{\mathrm{a}}$ & $1.5^{\mathrm{a}}$ & $2.3^{\mathrm{a}}$ \\
T2 & $2.7^{\mathrm{a}}$ & $2.3^{\mathrm{b}}$ & $2.7^{\mathrm{b}}$ \\
T3 & $2.9^{\mathrm{b}}$ & $3.1^{\mathrm{c}}$ & $3.1^{\mathrm{c}}$ \\
T4 & $3.3^{\mathrm{c}}$ & $3.8^{\mathrm{d}}$ & $3.3^{\mathrm{c}}$ \\
T5 & $3.4^{\mathrm{c}}$ & $4.1^{\mathrm{e}}$ & $3.3^{\mathrm{c}}$ \\
\hline $\boldsymbol{p}$ & $<\mathbf{0 . 0 0 1}$ & $<\mathbf{0 . 0 0 1}$ & $<\mathbf{0 . 0 0 1}$ \\
\hline
\end{tabular}

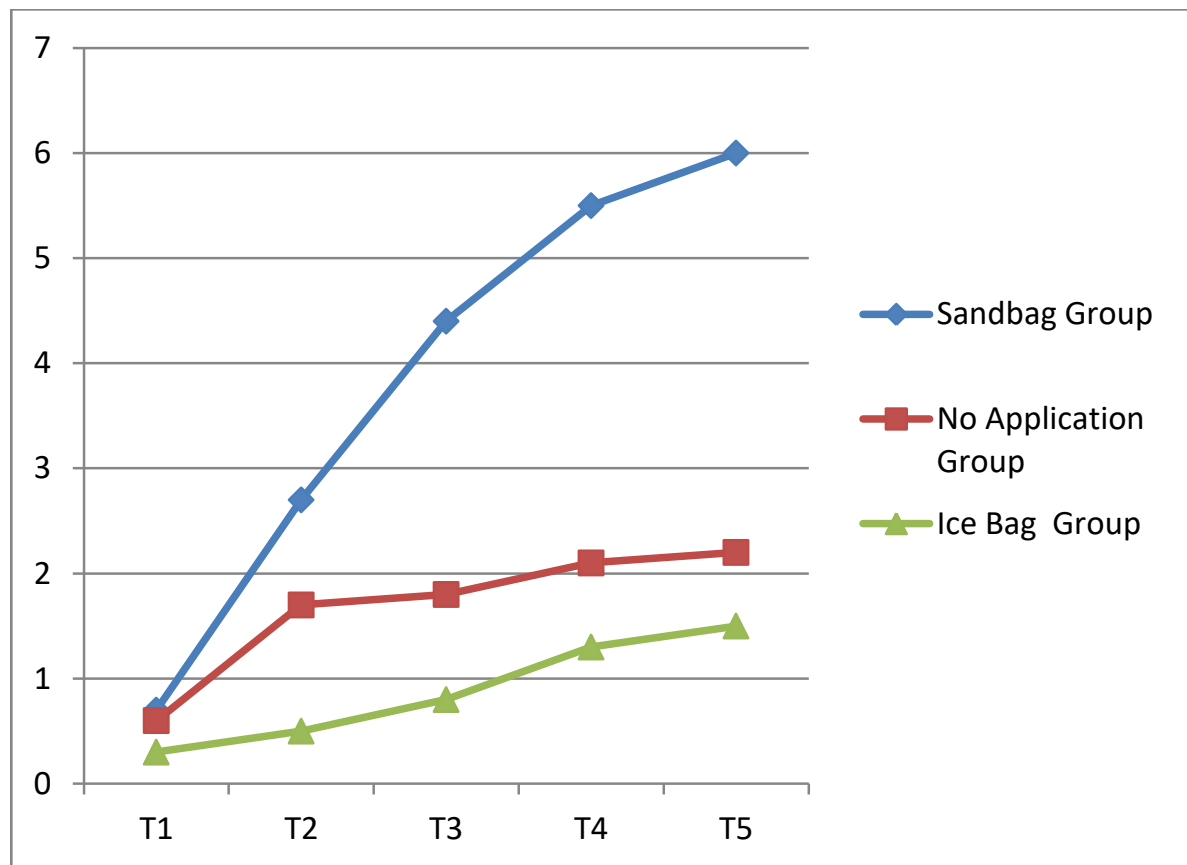

Figure 1. VAS score changes for three groups at the five time periods 